\title{
A Study of Students Perception Regarding Teacher Education through Distance Learning in Pakistan
}

\author{
Qadir Bukhsh \\ Department of Educational Training \\ The Islamia University of Bahawalpur, Pakistan
}

\begin{abstract}
The introduction of Distance System of education in Pakistan was started with the establishment of Allama Iqbal Open University (AIOU) in 1974. AIOU is a unique institution in Pakistan because of its philosophy, system, approach, functions and overall structure. It has many distinctive features i.e. specialized text books, allied material, use of interactive technologies, regional network, satellite tansmission, on line learning and broad cost and non- broad cost media for effective learning through Distance Education. The present study was undertaken to highlight the problems faced by the students of the Teacher Education Programmes of Open and Distance Learning institution in Pakistan. The study also measured the effectiveness of the different components of the Open and Distance Learning System such as admission, delivery system, assignments, students supports services, tutorial meetings, technological support, quality of the material, workshop, examination and results. To achieve the desired end all the students of M.A Teacher Education were taken as population of Region Bahawalpur of Allama Iqbal Open University Islamabad, Pakistan. 1250 students were taken as sample of the study. A questionnaire was the data collection tool. Data was analyzed in term of percentage and mean score. The major results of the study were as: (a) sufficient guidance counseling were available for admission (b) AIOU provided sufficient material for writing assignment (c) the attitude of the staff of the regional office was polite and cooperative (d) Students were satisfied with the quality of paper, printing and designing of the material of AIOU ( $f$ ) workshop of a course through AIOU covered all the content of the course $(\mathrm{g})$ Students were satisfied with the examination system of AIOU.
\end{abstract}

\section{Introduction}

Distance Education is learning system where the teaching behaviours are separate from the learning behaviours. The learner work- alone or in a groupsguided by study material arranged by the instructor who together with the tutors is in a location apart from the students, who however have the opportunity to communicate with tutor/tutors with the aid of one or more media by Rao.K.V [11]. Distance Education is any type of education that occurs while location, time or both separate the participants. In distance education, the teacher, through use of technology, delivers the instruction to a student at a separate location. The teacher then receives feedback, either immediate or delayed form the student by Siddique.H.M [12]. Distance Education has taken systematic teaching learning process to persons living in isolated areas where facilities for the traditional form of classroom teaching can not be developed. Further, as distance education addresses the needs of the specific target groups, there is great variation in the range of the programmes offered. Consequently, the basic characteristics of distance education are spatial separation of the teacher from the learner, an age heterogeneous learner group, easy availability and diversity in the nature of the programme offered by Rai.N.A [10]. Distance Education is now international recognized and accepted as an alternative channel for providing broader access to education in a cost effective manner; wider and diversified curricula and a means for continuing life long education by Rai, Bajpai and Singh [9].Distance Education has the potential and capacity to provide general education and professional education useful for the application useful for the application of the latest technology in the new millennium in all sectors of the development and face the force of globalization, deregulation, privatization and fast socio-economic changes through continuous education in latest developments to personnel engaged in these areas provided we maintain distance education system perfect, practical and operational by Geol. A and Geol. L. S [6].

Distance education is the realization of the concept of the globalization. Distance education has capacity to impart education efficiently and effectively for the large masses with the technological support. Distance education has brought an economic revolution in the modern world. Distance Education is open access to every one living in any part of the world. It is the mode of education having flexibility of time and space. Distance education is carried out with the help of 
media and computers. It is cost effective and fastest growing type of education. Distance education serves the persons living in the for flung areas with inadequate facilities of education as indicated by Rai, N.A [10] "Distance education has taken systematic teaching -learning process to persons living in isolated areas where facilities for the traditional form of class room teaching can not be developed. Further, as distance learning addresses the needs of specific target groups, there is a great variation in the range of programmes offered." Distance education eliminates the barriers to the access and extends the geographical reach. It emphasized on the creative approaches to the education as discussed by Khanna.S [7]: "Distance education is flexible and eliminates the barriers to the access and it extends the geographical reach of the courses. Distance education ensure the high retention rate among the students once enrolled and enable the tutors to handle more students without appreciably increasing their workload by using the technology. It improves the quality of the of the student learning experience, and thereby the reputation of the providing institution".

The distance mod of education can be implemented through the use of technology and in this form the teacher and students are separated from one another. Number of countries of the world have stared distance mode of education to increase the enrollment of the students as indicated by S.Manjulika [13] : "Distance education is one of the most important and widely proliferating educational phenomena worldwide. At least 30 countries have some form of "free-standing" distance education institutions to provide higher education opportunity to an increasing number of students, many of whom are adult students learning part-time in their homes and work places. Many believe that modern distance education, based on the digital and telecommunication technologies, will transform higher education as growing number of the adults and working people seek further education."

Distance education started in the form of correspondence courses for the educational development to facilitate adults who needs further education as pointed out by Panda.S [8] : "Distance education has evolved from traditional correspondence courses to online and networked learning. Today, a host of educational and training forms are processes are presented under the banner term 'distance education'. It is practiced through single mode distance teaching institutions, distance learning/educational development/flexible learning centers of higher and further education institutions and business enterprises, individual courses of academic programmes and schools of the studies". The mode of distance learning is internationally recognized as an alternative mean of education to the formal system of education. It is cost-effective as large masses can be facilitated by the use of technology. It provides strength to the idea of lifelong education as discussed by Rai, Bajpai and Singh[9] : "Distance education is now internationally recognized and accepted as an alternative channel for providing broader access to education in a cost effective manner; wider and diversified curricula and a means for continuing life long education.”

\section{Components of Distance Education}

AIOU has indicated the components of Distance Education as:

\section{- Course books}

The students who enroll with the university are provided with the course books especially prepared by the university on self instructional principles. However, at post graduate level reprints of foreign books are also provided to the students along with study guide.

\section{- Tutors}

In order to guide students during the semester part time tutors are appointed to evaluate the student's assignments and provide help to the students. Tutors are appointed by the regional office.

\section{- Tutorials}

During tutorial a student seeks continuous guidance through correspondence, personal visits or face to face group coaching during the tutorial. The tutorials are arranged at the study centre by the regional office.

\section{- Technological Support}

The radio/ TV programmes are broadcasted for the different courses according to the schedule to supplement, explain and demonstrate the material. In some courses recorded CDs are also provided to the students.

\section{- Assignments}

To ensure students study, they are asked to submit two assignments for half credit course and four for the full credit course. These assignments are evaluated by the tutors. A student fails to submit or pass the assignment is not allowed to sit in the final examination.

\section{- Workshops}

Practical training for some courses is arranged at the study centers to develop necessary skills in the 
students. In certain courses, students are required to attend workshops at the end of course and in this way they avail the opportunity to interact per group as well as the expert of the course.

\section{- Internship}

In some programmes, students are required to gain practical experience of related field and write analytical report e.g. business administration.

\section{- Final Examination}

Those students who passed assignments and workshop are eligible to sit in the final term examination. The final result of the course reflects combine performance of the students in assignments, workshop and final result.

\section{Distance Education System in Pakistan}

Distance system of education in Pakistan was started with the establishment of Allama Iqbal Open University. The Allama Iqbal Open University was established in 1974 under the name, people's Open University. It was renamed as Allama Iqbal Open University in 1977 at eve of national poet and philosopher, Allama Muhammad Iqbal. Allama Iqbal Open University was established under an act of parliament. It was the second Open University in the world, the first such university was established in UK in 1969.In many ways it is a unique institution, particularly in terms of employing Distance Education as its basic teaching methodology.

\subsection{Specialized Textbooks and Reading Material}

The University develops specialized textbooks and reading material to enable the students to study on the basis of self learning. To help them study at home, however, university provides support of radio and television programmes. The institution of education and technology (IET) produces high quality educational audio and video-cassettes, which enable the students to study at home more effectively.

\subsection{Use of Information Technology and Distance Education}

Recent innovations in the field of information and technology are making the system of Distance education more effective. As more and more students get access to personal computers and learn to use internet, teaching through distance education is becoming more effective.

\subsection{Qualified Teachers and their expertise for workshop and evaluation of assignments}

Qualified teachers from all over the country are mobilized as a part time tutors for students. The students study their material under the tutor's guidance and submit their assignments for the periodic evolution. Workshops at the end of the each semester further strengthen the process of learning.

\subsection{Regional Network of Allama Iqbal Open University}

The outreach system of the University in the form of its Regional Campuses/Centers is the back boon of the methodology. The University presently has 36 regional Campuses and centers in the country by AIOU, VC Report[3]

\subsection{Teacher Education through Distance Learning in Pakistan}

Faculty of Education in Allama Iqbal Open University, Islamabad was established in 1984. It is one of the largest faculties of the university both in terms of number and student enrolment. The faculty offers variety of programs in education and training teachers. These academic programmes range from primary teachers training to M.Phil and Ph.D levels and these programmes have earned distinctions for this university as a faculty of education. Faculty has following departments:

\subsection{Different programs offered by the faculty of education are as under:}

- PhD ( Education)

- M.Phil (Education)

- M.A (Education)

- B.Ed

- PG Diploma ( Educational Planning \& Management)

- $\quad$ PG Diploma (Special Education)

- $\quad$ C.T (Certificate of Teaching)

- Diploma (In Education 10+3 Model)

- New PTOC (Primary Teacher Orientation Course)

- $\quad$ SSC Level Courses (Related to the Faculty)

- HSSC Level Courses (Related to the Faculty)

- B.A Level Courses (Related to the Faculty)

\section{Objectives of the Study}

- To discuss the conceptual framework of open and distance learning system; 
- To identify the role open and distance learning system in promotion of teacher Education in Pakistan;

- To investigate problems faced by M.A (Education)/M.Ed students of AIOU in Region Bahawalpur;

- To suggest solution of problems faced by M.A (Education)/M.Ed students of AIOU in Region Bahawalpur;

\section{Research Methodology}

\subsection{Sample of the Study}

1620 students of M.A (Education) /M.Ed of spring 2007 enrolled in AIOU in Region Bahawalpur was the sample for the study. Region Bahawalpur consisted on four Districts of Southern Punjab i.e. Bahawalpur, Bahawalnagar, Rahim Yar Khan and Lothran.

\subsection{Development of Research Tool}

Since the study was descriptive in nature, therefore, survey approach was considered appropriate to collect the data. For this purpose a questionnaire on the five points scale was developed for students of M.A (Education)/ M.Ed of Region Bahawalpur.

\subsection{Administration of Research Tool}

The questionnaire was distributed to the students of M.A (Education) M.Ed of semester spring 2007 during the workshop and collected the researcher himself. 1250 respondents filled and returned the questionnaire.

\subsection{Data Analysis}

The data collected through questionnaire was coded and analyzed through Ms-Excel in term of percentage and mean scores were calculated. Scale values assigned to each of the five responses were as: Level of Agreement

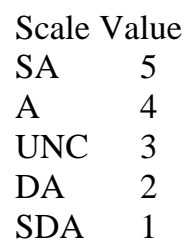

To calculate the mean score, following formula was used. $\frac{\text { Mean }}{\frac{(\text { FSAx5+Fax4+FUNCx3+FDAx2+FSDAx1) }}{N}}$ Score $=$

Where

FSA $=$ Frequency of strongly agreed

$\mathrm{FA}=\quad$ Frequency of agreed

FUNC= Frequency of uncertain

$\mathrm{FDA}=$ Frequency of disagreed

FSDA = Frequency of strongly disagreed

The findings from data analysis are presented below:

\section{Findings}

\section{1-Opinion of the Students about Admission}

It is evident from table 1 that majority of the respondents (68.80\%) agreed with the statement that you got admission notice for distance learning well in time. The mean score 3.4 supported the statement. A significant majority of the respondents $(89.28 \%$ with mean score 3.9) agreed with the statement that you got sufficient time to submit your admission application. Majority of the respondents (64.08\% with mean score 2.5) disagreed agreed with statement that you got prospectus easily. Majority of the respondents (64.08 \% with the mean score 3.6) agreed with the statement that you got sufficient guidance and counseling by the regional office. Majority of the respondents (68\%) agreed with the statement that you easily submit fee for the admission. The mean score 3.5 supported the statement. Majority of the respondents (65.36 \% with mean score 3.7) agreed with statement that you found sufficient informations on the web site of distance learning.

\section{2-Opinion of the Students about delivery of Material}

It is evident from table 2 that a significant majority of the respondents (91.28 \% with the mean score 4.1) agreed with the statement that you received the material packet by the institution of distance learning. Majority of the respondents (66.72 $\%$ with mean score 3.5 ) agreed with the statement that you received the material packet well in time. Only $54.48 \%$ with the mean score 3.2 agreed with the statement that you received complete material packet containing books, question papers for assignments, meeting schedule, schedule for assignment submission and students guide. A significant majority of the respondents (68.24 \% with mean score 2.2) disagreed with the statement that you are satisfied with delivery system of material. A significant majority of the respondents $(82.64 \%$ with 
mean score 3.7) agreed that you are satisfied with the delivery system of Pakistan post.

\section{3-Opinion of the Students about Assignments}

It is evident from table 3 that majority of the respondents (60.72 \% with mean score 2.6) agreed with the statement that you received sufficient material for completion of assignment. Majority of the respondents (61.92 \% with mean score 2.6) agreed with statement that you easily understood the material in preparation of assignments. Majority of the respondents $(69.60 \%)$ of the respondents agreed with the statement that you received tutor intimation well in time while the mean score is 3.6. A significant majority of the respondents (85.92 \% with mean score 1.6) disagreed with the statement that tutors returned your evaluated assignments with remarks. Majority of the respondents (73.04 \% with mean score 2.3) disagreed with the statement that you found complete answers from the material in preparation of the assignments.

\section{4-Opinion of the Students about Students Supports Services}

It is evident from table 4 that majority of the respondents (77.36 \% with mean score 4.1$)$ agreed with the statement that you got counseling regarding your problem from regional office. Majority of the respondents (70.32 \% with mean score 3.6) agreed with the statement that the attitude of the regional office personnel was polite and cooperative. Majority of the respondents (66.40\% with mean score 3.4) agreed with the statement that you found helpful both tutor and staff of regional office.

\section{5-Opinion of the Students about Tutorial Meetings}

It is evident from table 5 that majority of the respondents (77.84 \% with mean score 2.1$)$ disagreed with the statement that you got intimation of the study centre. Majority of the respondents (76.08\% with mean score 3.6) disagreed with the statement that you found your tutor available according to schedule. A significant majority of the respondents (88.72\% with mean score 1.8) disagreed with the statement that tutors provided sufficient guidance during tutorial meetings. A significant majority of the respondents (84.88\% with mean score 1.8$)$ disagreed with the statement that tutorial meetings enhanced the knowledge of the course. Majority of the respondents (74.64 \% with mean score 2.3) disagreed with the statement that tutorial meetings resolved students difficulties concerning understanding of material.

\section{6-Opinion of the Students about quality of Material}

It is clear from the table-6 that majority of the respondents (79.44\% with mean score 3.8) agreed with the statement that you are satisfied with quality of paper, printing and designing of material. Majority of the respondents (70.86 \% with mean score 3.6) agreed with statement that the language of the material was easy to understand. Majority of the respondents (77.42 \% with mean score 3.8) agreed with the statement that the content covered all the aspects of the course. Majority of the respondents (67.24 \% with mean score 3.5) agreed with statement that the material was self explanatory. $53.60 \%$ of the respondents with mean score 2.6 disagreed with statement that the material consisted on updated, modern and latest knowledge of subject. Majority of the respondents (60.30\% with mean score 3.4) agreed with statement that the material was in accordance with the distance learner's need.

\section{7-Opinion of the students about workshop}

It is evident from the table- 7 that majority of the respondents (76024\% with mean score 3.7 ) agreed with the statement that you received intimation of the workshop well in time. Majority of the respondents (66.80\% with mean score 3.6) agreed with statement that the environment of the classroom in the workshop was supportive for teaching learning. Majority of the respondents (68.72\% with mean score 3.5) agreed with statement that resource persons were punctual and regular during workshop. Majority of the respondents (66.48\% with mean score 3.6) agreed with statement that the lectures of the resource persons were effective for learning. A significant majority of the respondents $(80.64 \%$ with mean score 4.0) agreed with the statement that workshop covered all the content of the course. Majority of the respondents (68.80\% with mean score 3.6) agreed with statement that you are satisfied with the facilities at the workshop venue.51.76 \% of the respondents with mean score 2.6 disagreed with the statement that the duration of the workshop was sufficient. A significant majority of the respondents (89.76 \% with mean score 1.8) disagreed with the statement that the resource persons utilized multimedia and projector as $\mathrm{A} / \mathrm{V}$ aid. Majority of the respondents (60.96 \% with mean score 3.4) agreed with statement that you are satisfied with the professional knowledge and skill of the resource persons. $50.75 \%$ of the respondents with mean score 3.1 agreed with statement that the venue of the workshop was easy to access. 


\section{8-Opinion of the students about evaluation and examination}

It is clear from table 8 that majority of the respondents (70.4 5 with mean score 3.7) agreed with statement that you received roll number slip and date sheet before the examination. Majority of the respondents (66.56\% with mean score 3.5) agreed with statement that you are satisfied with the distribution of the marks for assignments, workshop and final written examination. Majority of the respondents (67.82 \% with mean score 3.6) agreed with statement that there were sufficient facilities at the examination centre. Majority of the respondents (64.92 \% with mean score 3.4) agreed with statement that the attitude of the examiners was polite and positive at examination centre. Majority of the respondents (76.88 \% with mean score 3.0) agreed with the statement that the question papers covered all the content of the courses. Majority of the respondents (71.36 \% with mean score 3.8) agreed with statement that you are satisfied with the examination system of distance institution.

\section{9-Opinion of the students about results}

It is clear from the table 9 that slight majority of the respondents (56.88\% with mean score 3.3 ) agreed with statement that result declared well in time. Majority of the respondents $(70.80 \%$ with mean score 3.7) agreed with statement that you received result card after declaration of result. Majority of the respondents (66.80\% with mean score 3.1) were uncertain about the statement that the correction process of the result card was easy. A significant majority of the respondents (82.16\% with mean score 3.9) agreed with statement that you got result card by post. A significant majority of the respondents (80.32\% with mean score 2.0 ) disagreed with the statement that you got your result card by internet.

\section{Conclusions}

- Majority of the respondents agreed that they got admission notice, sufficient time to apply, sufficient guidance by Regional office and sufficient Informations on the web site of the distance learning institution.

- Majority of the respondents agreed that they received material packet well in time from institution.

- Majority of the respondents agreed that they received sufficient, easy and understandable material for assignments from distance institution.
- Majority of the respondents agreed that Regional office provide counseling , tutor provide help and cooperate during study.

- Majority of the respondents disagreed that they received intimation and guidance during tutorial meeting.

- Majority of the respondents agreed that they received quality printed and self explanatory material which fulfill the needs of the distant learner.

- Majority of the respondents were satisfied with environment, resource persons, effective lectures, facilities, professional knowledge and skill of the resource persons and venue of the workshop.

- Majority of the respondents were satisfied with distribution of the marks for assignments, workshop and final written examination, facilities at examination centre, attitude of the examiners, question papers and examination system.

- Majority of the respondents were satisfied with the declaration and delivery of the result card of distance learning institution

\section{Recommendations}

- There may be started online admission to provide access and increase enrollment of the students.

- There may be e-submission of the assignments and e-assessments by the tutors to improve the feed back to the students.

- There may be effective monitoring system for tutorial meeting by the Regional Office of AIOU to improve the quality of education.

- There may be provided updated material having latest knowledge of the subject for the effective learning by the students.

- The duration of the workshop may be increased to provide professional skill and face to face interaction with the experts.

- Multimedia and projectors may be used during workshop for effective learning and comprehension.

- Delivery system of the material may be improved and the soft copy of the material may be mailed to the students ID

\section{References}

[1] AIOU (1999).25 years of AIOU (1974-1999). Allama Iqbal Open University Islamabad: Pakistan.

[2] AIOU (2000). A Profile. Allama Iqbal Open University Islamabad: Pakistan.

[3] AIOU (2005). Vice Chancellor's Annual Report.Allama Iqbal Open University Islamabad: Pakistan. 
[4] AIOU (2007). In Brief. Allama Iqbal Open University Islamabad: Pakistan.

[5] AIOU (2007). Manual of Teaching Practice, Allama Iqbal Open University Islamabad: Pakistan.

[6] Goel.A and Goel.L.S (2000). Distance Education in $21^{\text {st }}$ Century, Deep \& Deep publishers, Rajouri Garden, India: New Delhi.

[7] Khanna.S (2006). Relevance of Distance Education, Max Ford Books: India

[8] Panda.S (2003). Planning and Management of Distance Education,120 Pentonville Road London N1 9JN, UK.

[9] Rai, Bajpai and Singh (2007). Growth and Development of Distance Education, APH

Publishing Corporation, Ansari Road, Darya Ganj, India: New Delhi.

[10] Rai, N.A (2000). Distance Education Open Learning VS Virtual University Concepts, E-35/103, Jwahar Park Laxmi Nagar, New Delhi: India.

[11] Rao, K.V (2003). Distance Education, 5, Ansari Road, Darya Ganj New Delhi: India.

[12] Siddique.H.M (2004). Distance Learning Technologies in Education, 5, Ansari Road, Darya Ganj New Delhi: India.

[13] S. Manjalika (1999). Unexplored dimensions of Open Universities, 5, Ansari Road, Darya Ganj New Delhi: India. 